\title{
Acute Bovine Laminitis: A New Induction Model Using Alimentary Oligofructose Overload
}

\author{
M. B. Thoefner, ${ }^{1}$ C. C. Pollitt, ${ }^{2}$ A. W. van Eps, ${ }^{2}$ G. J. Milinovich, ${ }^{2}$ \\ D. J. Trott, $^{2}$ O. Wattle, ${ }^{3}$ and P. H. Andersen ${ }^{1}$ \\ ${ }^{1}$ Large Animal Surgery, Department of Large Animal Sciences, Clinical Institute, \\ Royal Veterinary and Agricultural University of Copenhagen, Denmark \\ ${ }^{2}$ School of Veterinary Science, University of Queensland, Australia \\ ${ }^{3}$ Department of Large Animal Clinical Studies, \\ Swedish University of Agricultural Sciences, \\ Uppsala, Sweden
}

\section{ABSTRACT}

Twelve dairy heifers were used to examine the clinical response of an alimentary oligofructose overload. Six animals were divided into 3 subgroups, and each was given a bolus dose of 13,17 , or $21 \mathrm{~g} / \mathrm{kg}$ of oligofructose orally. The control group $(\mathrm{n}=6)$ was sham-treated with tap water. Signs of lameness, cardiovascular function, and gastrointestinal function were monitored every $6 \mathrm{~h}$ during development of rumen acidosis. The heifers were euthanized 48 and $72 \mathrm{~h}$ after administration of oligofructose. All animals given oligofructose developed depression, anorexia, and diarrhea 9 to $39 \mathrm{~h}$ after receiving oligofructose. By 33 to $45 \mathrm{~h}$ after treatment, the feces returned to normal consistency and the heifers began eating again. Animals given oligofructose developed transient fever, severe metabolic acidosis, and moderate dehydration, which were alleviated by supportive therapy. Four of 6 animals given oligofructose displayed clinical signs of laminitis starting 39 to $45 \mathrm{~h}$ after receiving oligofructose and lasting until euthanasia. The lameness was obvious, but could easily be overlooked by the untrained eye, because the heifers continued to stand and walk, and did not interrupt their eating behavior. No positive pain reactions or lameness were seen in control animals. Based on these results, we conclude that an alimentary oligofructose overload is able to induce signs of acute laminitis in cattle. This model offers a new method, which can be used in further investigation of the pathogenesis and pathophysiology of bovine laminitis.

(Key words: bovine, laminitis, lameness, oligofructose)

Abbreviation key: PAO = postadministration of oligofructose, $\mathbf{P C V}$ = packed cell volume.

Received October 28, 2003.

Accepted June 3, 2004. $\mathrm{dk}$.

\section{INTRODUCTION}

Lameness and its welfare implication have become more widely recognized problems in recent years particularly in intensive dairy farming (Hoblet et al., 2000; Nelson and Cattell, 2001). Many of the major claw horn lesions causing lameness are believed to result from socalled laminitis. However, in many cases the various authors were referring to pododermatitis aseptica diffusa (sole hemorrhage) and to associated severe lesions such as pododermatitis circumscripta (sole ulceration) and had no direct evidence that the lamellae themselves were directly affected. Nevertheless, experimental studies and epidemiological surveys have identified risk factors that are associated with an increased prevalence of laminitis-associated lesions: housing (Vermunt and Greenough, 1996; Webster, 2001), management (Colam-Ainsworth et al., 1989; Bergsten, 1994), nutrition (Manson and Leaver, 1989), and calving (Offer et al., 2000). However, despite considerable research over recent years, the causal agents and the pathophysiological mechanisms of bovine laminitis remain unclear. A plausible and reproducible experimental model for the study of bovine laminitis does not currently exist.

Analysis of clinical cases precipitated by feeding a large amount of readily fermentable carbohydrate shows that signs of laminitis are often preceded by ruminal acidosis or gastrointestinal disease (Maclean, 1966; Yeruham et al., 1999). Different experimental models have tried to mimic this situation, by the administration of substances into the rumen to cause changes in the gastrointestinal environment. Attempts to induce acute laminitis with intraruminal infusion of lactic acid were reported to be partially successful in sheep (Morrow et al., 1973) but unrewarding in cattle (Andersson, 1981). Several studies have unsuccessfully tried to induce laminitis using an alimentary carbohydrate overload model (Hyldgaard-Jensen and Simesen, 1966; Boosman et al., 1990; Momcilovic et al., 2000). Although 3 of 6 steers showed very early signs of laminitis 12 to 
$16 \mathrm{~h}$ after starch overload (Suber et al., 1979), the clinical signs defining acute laminitis were not specified and it was unclear how comparison between animals was carried out. Christmann et al. (2002) evaluated hemodynamics in the digits of anesthetized steers given a grain overload. A successful induction of acute laminitis was reported without explaining how the criteria used for a positive diagnosis relate to the clinical syndrome.

A relationship between rumen acidosis and detection of endotoxin in the rumen generated the hypothesis of endotoxin being the trigger factor for laminitis. However, endotoxin injections have not been shown to induce clinical signs of acute laminitis in cattle (Boosman et al., 1991; Ohtsuka et al., 1997). Histamine and other vasoactive amines have been suggested as causal factors of laminitis. Nilsson (1963) reported that subcutaneous injections of histamine induced acute laminitis in cattle. Takahashi and Young (1981) were partially successful in their attempts to induce clinical laminitis when grain overload was combined with histamine administration. Unsuccessful attempts to reproduce the model were later reported by Boosman (1990), leaving the role of histamine debatable.

In summary, the reports on the potential of starch to induce clinical laminitis seem conflicting, and it becomes tempting to hypothesize the involvement of other carbohydrates. The results from a recent study undertaken by Pollitt and van Eps (accepted) demonstrated that alimentary oligofructose overload consistently resulted in the development of acute laminitis in horses. Oligofructose, as fructan, is one of the most abundant nonstructural carbohydrates in several plant species including many grasses (Cairns and Longland, 1998). Plants accumulate fructan depending on the prevailing growth conditions. Stressful conditions such as high light intensity and low temperature (comparable to spring and autumn in temperate climates) can result in very high fructan concentrations (Longland and Cairns, 2000).

Therefore, the purpose of the present study was to examine the clinical response of cattle dosed with an alimentary overload of oligofructose, with particular emphasis on development of laminitis.

\section{MATERIALS AND METHODS}

\section{Animals}

Twelve nonpregnant dairy heifers (3 Jersey, 6 Holstein-Friesian, 2 Ayrshire, and 1 Guernsey) between 325 and $505 \mathrm{~kg}$ (mean $=408 \mathrm{~kg})$ were subjected to a 4 wk period of close handling and acclimatization. The animals originated from 3 dairy farms (all animals could not be purchased from same source), all of which kept heifers at grass from an early age. During acclima- tization, the animals were kept in a paddock with a soft surface and were fed mixed grass-lucerne (alfalfa) hay ad libitum to ensure good ruminal function. At the end of this period, all animals tolerated clinical examination without any excitement (no changes in heart or respiratory rates), they could be walked by hand, accepted lifting of the distal front limb, foot palpation, and hoof testing (hind limbs were not examined for safety reasons). At the beginning of the trial, the heifers were assigned to 2 groups of 6 animals: the treatment group was challenged with oligofructose (Raftilose P95; Orafti Group, Tienen, Belgium), and the control group was given tap water $(6 \mathrm{~L}$ per $100 \mathrm{~kg})$. The oligofructose group was further divided in subgroups of 2 animals, each given a bolus dose of 13,17 , or 21 $\mathrm{g} / \mathrm{kg}$ of oligofructose. Oligofructose was dissolved in tap water (solubility $=80 \mathrm{~g} / 100 \mathrm{~mL}$ of water; $6 \mathrm{~L}$ per 100 $\mathrm{kg}$ heifer was used) and administered into the rumen by stomach tube. Five percent of the main dose was given as a priming dose twice a day for $3 \mathrm{~d}$ before the experiment, to gradually allow adjustment of the forestomach microbiota to the new source of carbohydrate.

\section{Data}

Baseline information on the cardiovascular (heart rate, packed cell volume, and standard base excess) and gastrointestinal status (rumen and feces $\mathrm{pH}$, rumen contractions, and rectal temperature) as well as signs of lameness (hoof testing, digital pulse strength, and lameness examination) were recorded before the first priming dose (at $-72 \mathrm{~h}$ ) and during the priming period (at -48 and $-24 \mathrm{~h}$ ). The clinical response was monitored at the time of administration of the main dose, and then at 6 -h intervals, starting at $9 \mathrm{~h}$ postadministration of oligofructose (PAO), until the heifers were euthanized. Time points for observation are shown in Table 1.

At the beginning of the study, the response to oligofructose was unknown and a careful approach was taken to avoid severe distress in a large number of animals. Initially, the response was observed in only 2 animals given the lowest dose of oligofructose. No unexpected or uncontrollable side effects were noticed. These 2 animals were euthanized at $72 \mathrm{~h}$ PAO. The decision to shorten the study period and euthanize the remaining 10 animals at $48 \mathrm{~h}$ PAO was made because lameness was observed as an early sign.

All animals had catheters placed in the jugular vein before the main dose of oligofructose was given. A handheld blood-gas analyzer (i-STAT; Sensor Devices Incorporated, Waukesha, WI) was used to monitor the resulting metabolic acidosis and degree of dehydration to enable early alleviation with supportive therapy. A pilot study showed that the i-STAT resulted in a slight un- 
Table 1. Results of hoof testing in 6 animals given oligofructose versus 6 control animals. Oligofructose was administered at $0 \mathrm{~h}$. Only pain reaction in the front claws was examined. Independent monitors without prior knowledge of previous recordings monitored animals in a rotation system.

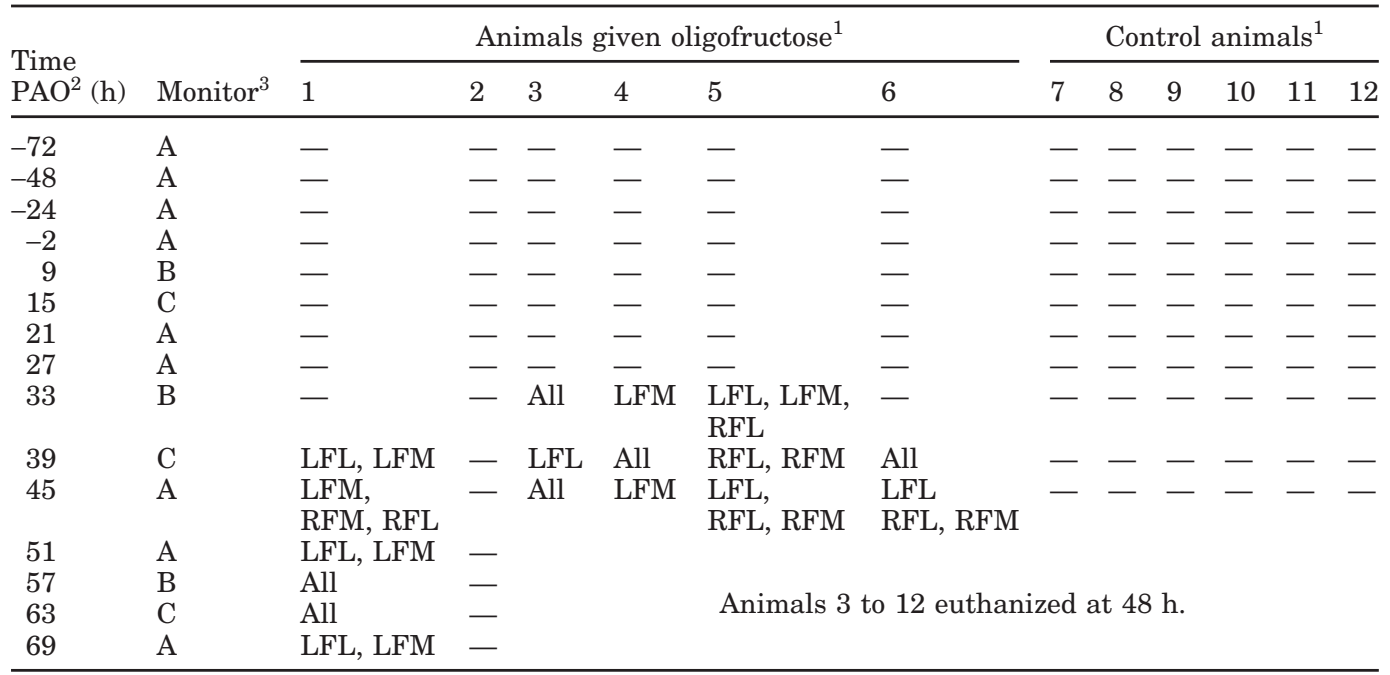

${ }^{1}$ Pain reactions: $-=$ no pain reaction; $L F L=$ pain reaction in left front lateral claw; $L F M=$ pain reaction in left front medial claw; $\mathrm{RFL}$ = pain reaction in right front lateral claw; $\mathrm{RFM}$ = pain reaction in right front medial claw; All = pain reaction in all 4 front claws.

${ }^{2} \mathrm{PAO}=$ Postadministration of oligofructose.

${ }^{3} \mathrm{~A}, \mathrm{~B}, \mathrm{C}=3$ veterinarians who monitored the animals.

derestimation of packed cell volume (PCV), and an equation (actual PCV $=0.99 \times$ i-STAT PCV $+3.04, \mathrm{n}=$ 16) was therefore used to adjust the readings. Intravenous fluid therapy was instituted if PCV increased to more than $42 \%$. Sodium bicarbonate was administered orally or i.v. if standard base excess dropped below -8 $\mathrm{mmol} / \mathrm{L}$. Signs of lameness were identified by observing the animal standing in the box, walking or trotting in a straight line, and while the animal was turned in small circles on a hard surface. The 3 monitors (all veterinarians), blinded to previous results, recorded the clinical responses of the animals in a nonconsecutive rotation. Lameness was classified as none, mild, moderate, or severe. 'Mild lameness' was recorded if slight lameness was seen when turning the heifers in circles or if the lameness was detectable only in the trot (e.g., head nodding or other uneven or asymmetric movement of hind or front). 'Moderate lameness' was recorded if lameness was obvious when walking and if the animal was reluctant to walk from soft bedding to a hard concrete surface (tender feet). 'Severe lameness' was recorded if lifting of feet was impossible or if animals only could stand for a few minutes.

In the present paper, acute laminitis is defined as a clinical disease with a rapid onset of foot pain and detectable lameness, which is seen shortly after alimentary overload of readily fermentable carbohydrate. Signs of claw inflammation (e.g., warmth and increased pulsation) may be present but no claw lesions can be identified visually (Ossent et al., 1997).

\section{Statistical Analyses}

An animal was regarded as having developed clinical laminitis if 2 consecutive positive hoof tests (positive pain reaction) were obtained $6 \mathrm{~h}$ apart in the same claw, and lameness was observed independently by at least 2 of the 3 monitors. The null hypothesis of no association between exposure to oligofructose and development of laminitis was examined using one-sided Fisher's exact test at a 5\% level of statistical significance. The effect of oligofructose on other clinical variables was compared graphically; however, observations obtained between 45 and $72 \mathrm{~h}$ PAO for the 2 animals euthanized at $72 \mathrm{~h}$ PAO were not used. Results from the 3 groups given different oligofructose dosages were not pooled so that trends in the dose-response relationship could be examined. The mean value of observations in the control group was compared with the mean value in the groups given the 3 doses of oligofructose (GraphPad Prism, version 4.00 for Windows, GraphPad Software, San Diego, CA).

The protocol was approved by the Animal Ethics Committee, The University of Queensland, and animals were inspected by the Animal Welfare Officer during the study (animal ethics approval certificate SVS/125/ 


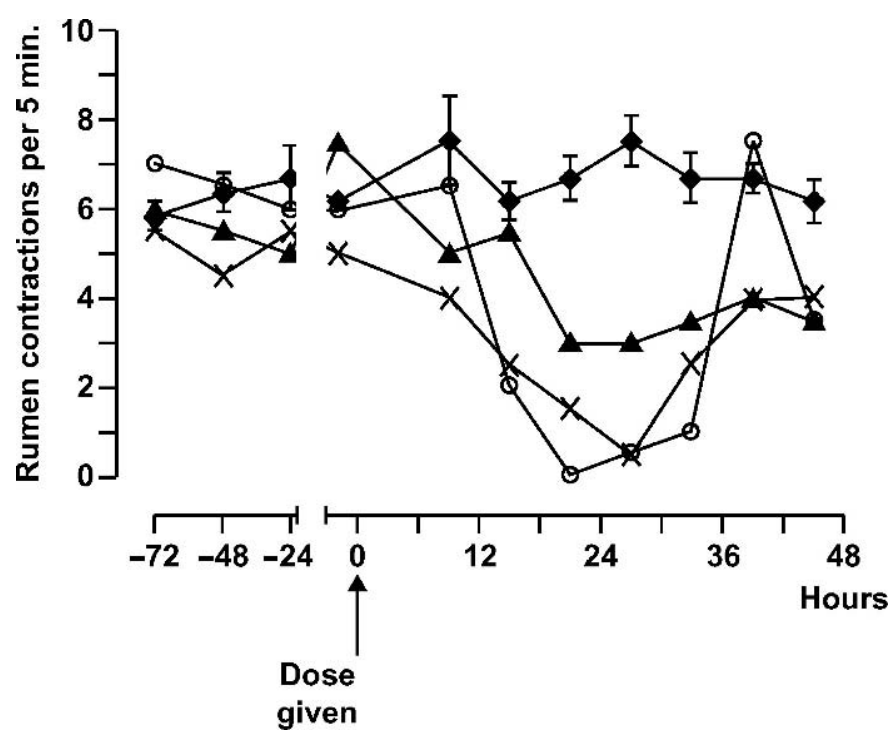

Figure 1. Clinical response to oligofructose. Number of rumen contractions is depicted as mean values for 6 control heifers ( $)$ and heifers administered 3 different doses of oligofructose $(n=2$ per dosage): $13 \mathrm{~g} / \mathrm{kg}(\bigcirc), 17 \mathrm{~g} / \mathrm{kg}(\boldsymbol{\Lambda})$, and $21 \mathrm{~g} / \mathrm{kg}(\mathbf{x})$. The standard error of the mean is not shown for groups given oligofructose due to low numbers in each group.

02/RVA/UC). The heifers were euthanized by captive bolt and exsanguination at the end of the study. A postmortem examination of the gastrointestinal tract was carried out and claw biopsies were processed for histol-

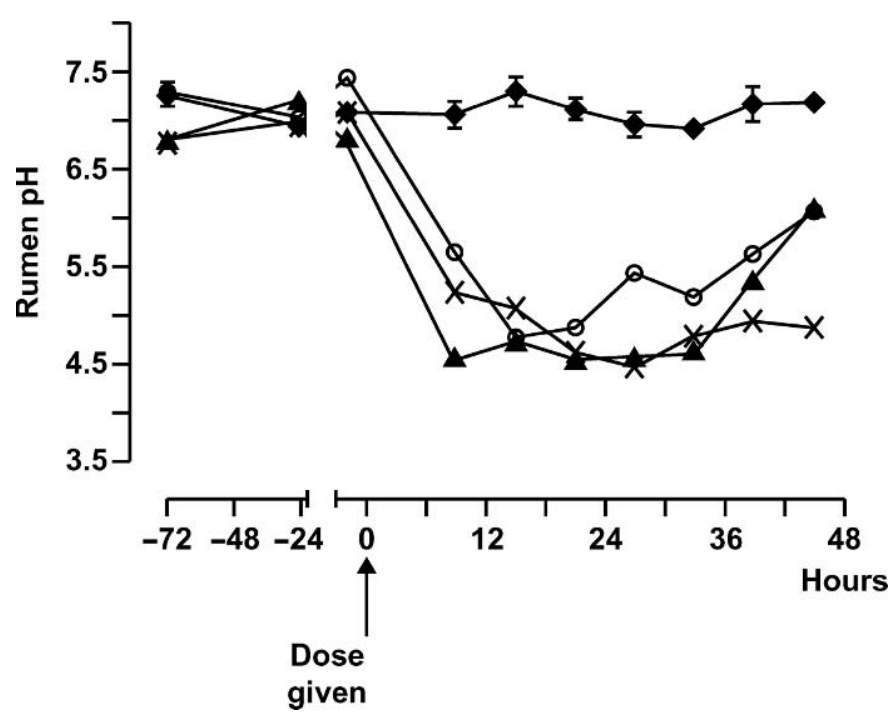

Figure 2. Clinical response to oligofructose. Changes in rumen $\mathrm{pH}$ are depicted as mean values for 6 control heifers $(\bullet)$ and heifers administered 3 different doses of oligofructose ( $n=2$ per dosage): 13 $\mathrm{g} / \mathrm{kg}(\bigcirc), 17 \mathrm{~g} / \mathrm{kg}(\boldsymbol{\Lambda})$, and $21 \mathrm{~g} / \mathrm{kg}(\mathbf{x})$. The standard error of the mean is not shown for groups given oligofructose due to low numbers in each group.

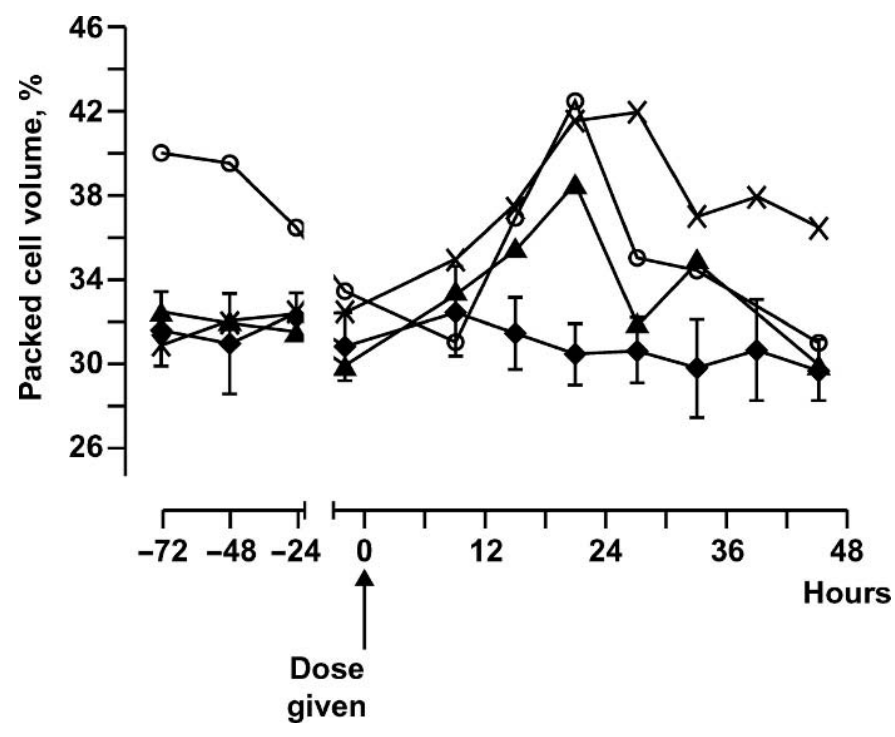

Figure 3. Response to oligofructose. Changes in packed cell volume $(\mathrm{PCV})$ are depicted as mean values for 6 control heifers $(\checkmark)$ and heifers administered 3 different doses of oligofructose ( $=2$ per dosage): 13 $\mathrm{g} / \mathrm{kg}(\mathrm{O}), 17 \mathrm{~g} / \mathrm{kg}(\boldsymbol{\Delta})$, and $21 \mathrm{~g} / \mathrm{kg}(\mathbf{x})$. The standard error of the mean is not shown for groups given oligofructose due to low numbers in each group.

ogy. Preliminary findings from histopathological examination of claw biopsies are presented in this paper. A detailed characterization will be provided in a separate publication.

\section{RESULTS}

All heifers given oligofructose drank large amounts of water (approximately 50 to $80 \mathrm{~L} / \mathrm{head}$ ) during the first $12 \mathrm{~h}$ PAO. In 3 animals, fluid distension of the rumen was palpated at $9 \mathrm{~h} \mathrm{PAO}$, but thereafter, neither gas nor fluid distension of the rumen was observed. All animals given oligofructose developed profuse, watery diarrhea, which began at $9 \mathrm{~h}$ and continued until $33 \mathrm{~h}$ in 3 animals, until $39 \mathrm{~h}$ in 2 , and until $45 \mathrm{~h}$ PAO in 1 animal. During this period, animals were depressed and stopped eating. The 2 animals given the highest oligofructose dose $(21 \mathrm{~g} / \mathrm{kg})$ stopped eating at $9 \mathrm{~h}$, the remaining 4 stopped by $15 \mathrm{~h}$ PAO. Rumen contractions ceased or decreased from 9 to $15 \mathrm{~h}$ in animals given oligofructose, and increased again slowly from $27 \mathrm{~h} \mathrm{PAO}$ (Figure 1). The change in rumen contractions coincided with change in rumen $\mathrm{pH}$ and diarrhea (Figure 2). Changes in fecal $\mathrm{pH}$ appeared to follow the changes in rumen $\mathrm{pH}$ (data not shown). All animals started to eat and ruminate without rumen fluid replacement being necessary. No changes in the above variables were recorded in the control group.

All animals given oligofructose had a short-term increase in PCV that peaked around $21 \mathrm{~h}$ PAO (mean 


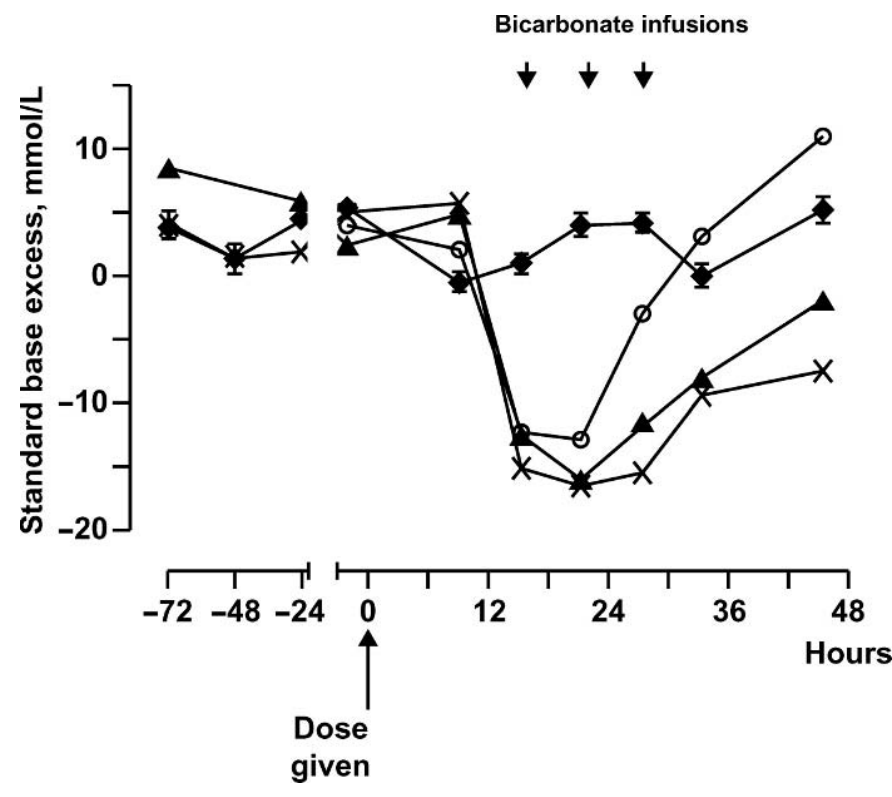

Figure 4. Response to oligofructose. Changes in standard base excess are depicted as mean values for 6 control heifers $(\bullet)$ and heifers administered 3 different doses of oligofructose $(\mathrm{n}=2$ per dosage): $13 \mathrm{~g} / \mathrm{kg}(\bigcirc), 17 \mathrm{~g} / \mathrm{kg}(\mathbf{\Lambda})$, and $21 \mathrm{~g} / \mathrm{kg}(\mathbf{x})$. The standard error of the mean is not shown for groups given oligofructose due to low numbers in each group.

PCV $\geq 38 \%$ in all groups). The increase tended to be more pronounced and prolonged in the 2 animals receiving the high dose (Figure 3). From $9 \mathrm{~h}$ PAO, all animals given oligofructose developed a profound metabolic acidosis (mean standard base excess below $-12 \mathrm{mmol} / \mathrm{L}$ in all groups) (Figure 4). Dehydration and metabolic acidosis was further reflected in heart rates, which appeared to increase more in animals given the highest dose of oligofructose ( $>90$ beats/min at 15 to $39 \mathrm{~h} \mathrm{PAO}$ ) (Figure 5). Five animals of 6 exposed to oligofructose developed a transient episode of fever, which coincided with the presence of diarrhea. It appeared that higher doses of oligofructose correlated with increases in rectal temperature (Figure 6). Observations for control animals were within normal reference intervals throughout the study.

Intravenous infusions of 5\% sodium bicarbonate were necessary to alleviate metabolic acidosis in all animals given oligofructose. The 2 animals given $13 \mathrm{~g} / \mathrm{kg}$ of oligofructose received $500 \mathrm{~mL}$ of bicarbonate i.v. at 15 and $21 \mathrm{~h} \mathrm{PAO}$, and received an oral dose of bicarbonate (300 $\mathrm{g}$ at $21 \mathrm{~h}$ PAO), which tended to overcorrect the acidosis (Figure 4). Both heifers given $17 \mathrm{~g} / \mathrm{kg}$ of oligofructose received $1000 \mathrm{~mL}$ of bicarbonate i.v. at 21 and $27 \mathrm{~h}$ $\mathrm{PAO}$ and an additional $500 \mathrm{~mL}$ of bicarbonate was given i.v. at $27 \mathrm{~h}$ PAO. Animals given $21 \mathrm{~g} / \mathrm{kg}$ of oligofructose received bicarbonate i.v. at $15(500 \mathrm{~mL}), 21(1000 \mathrm{~mL})$, and $27 \mathrm{~h}$ PAO $(1000 \mathrm{~mL})$. One of the heifers given the

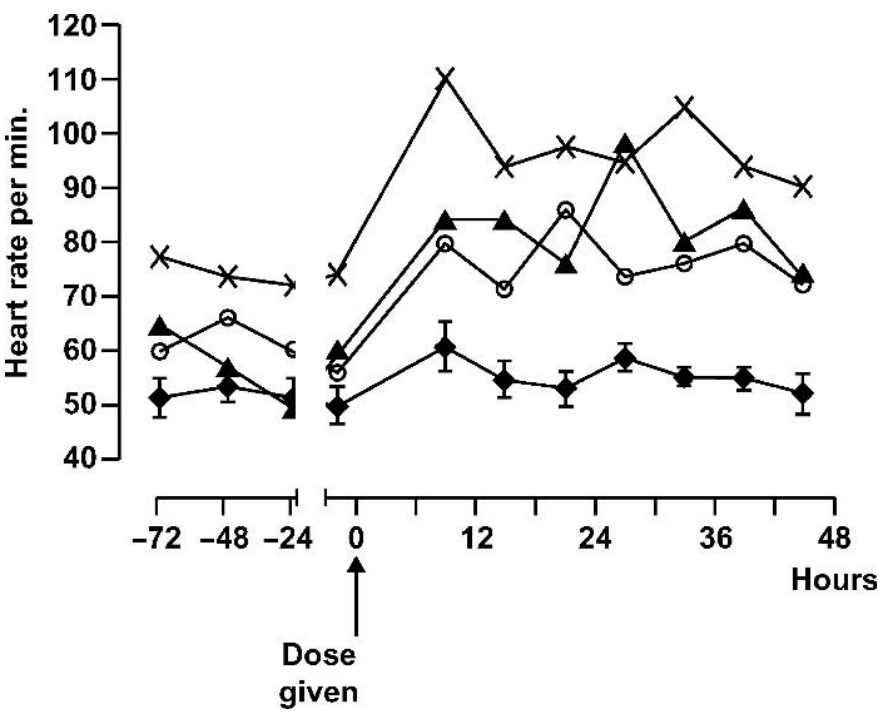

Figure 5. Clinical response to oligofructose. Changes in heart rate are depicted as mean values for 6 control heifers $(\diamond)$ and heifers administered 3 different doses of oligofructose ( $\mathrm{n}=2$ per dosage): 13 $\mathrm{g} / \mathrm{kg}(\mathrm{O}), 17 \mathrm{~g} / \mathrm{kg}(\mathbf{\Lambda})$, and $21 \mathrm{~g} / \mathrm{kg}(\mathbf{x})$. The standard error of the mean is not shown for groups given oligofructose due to low numbers in each group.

highest dose of oligofructose also needed $500 \mathrm{~mL}$ i.v. at 39 and $45 \mathrm{~h}$ PAO.

Four animals with high PCV received i.v. fluids, and all animals given oligofructose received 300 to $650 \mathrm{~mL}$ of calcium borogluconate (400 g/L, Unical C.B.G., Mav-

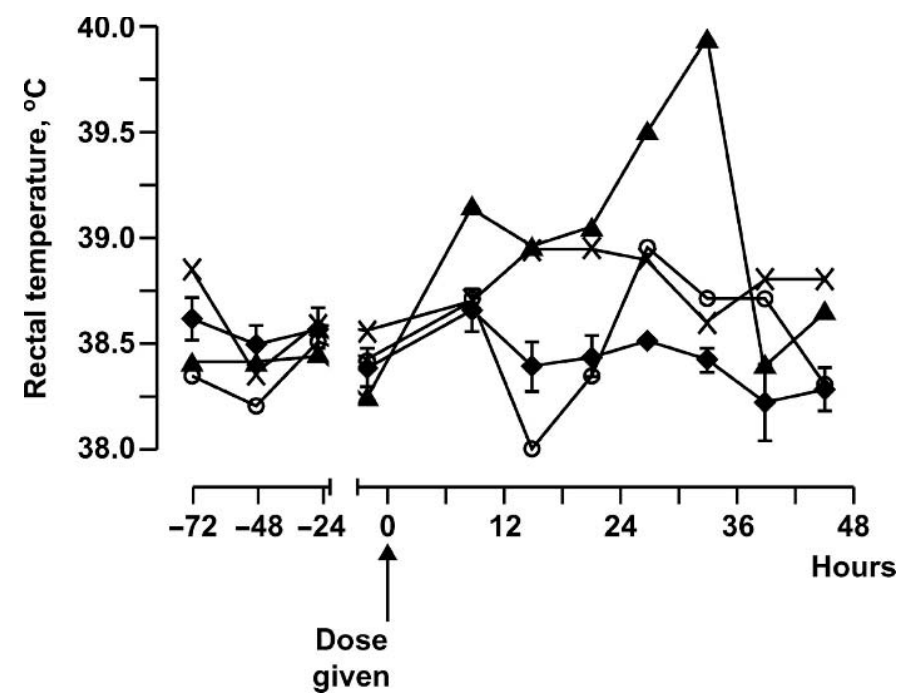

Figure 6. Clinical response to oligofructose. Changes in rectal temperatures are depicted as mean values for 6 control heifers $(\bullet)$ and heifers administered 3 different doses of oligofructose $(n=2$ per dosage): $13 \mathrm{~g} / \mathrm{kg}(\bigcirc), 17 \mathrm{~g} / \mathrm{kg}(\mathbf{\Delta})$, and $21 \mathrm{~g} / \mathrm{kg}(\mathbf{x})$. The standard error of the mean is not shown for groups given oligofructose due to low numbers in each group. 
lab, Pty. Ltd., Slacks Creek, Queensland, Australia) i.v. to treat signs of ataxia. Ataxia was observed 15 or 21 $\mathrm{h}$ PAO and signs disappeared quickly after infusion of calcium borogluconate.

The results of hoof testing are shown in Table 1 . Five of 6 animals given oligofructose had at least 2 consecutive positive pain reactions in the same claw. All positive pain reactions were strong and were observed at $33 \mathrm{~h} \mathrm{PAO}$ or later. Positive pain reactions were not observed in control animals. Palpation of digital arteries, in an attempt to detect increased pulse amplitudes during development of laminitis, appeared to be highly variable between observers and animals, and without any obvious relationship to oligofructose exposure (data not shown). Digital pulse amplitude was therefore discarded in further analyses.

Lameness was observed in animals $1,3,4$, and 6 from $39 \mathrm{~h} \mathrm{PAO}$ or later. Lame animals were distributed almost equally between the 3 dose groups: 1 of 2 heifers that received $13 \mathrm{~g} / \mathrm{kg}, 2$ of 2 that received $17 \mathrm{~g} / \mathrm{kg}$, and 1 of 2 that received $21 \mathrm{~g} / \mathrm{kg}$. Lameness was obvious on walking in animals 1,3 , and 6 , whereas it was only detectable in the trot in animal 4. All lame heifers continued to display lameness at a constant level for the duration of the study. Two heifers given oligofructose showed no signs of lameness. None of the control animals displayed signs of lameness during the study.

Four of the 6 animals given oligofructose had 2 consecutive positive pain reactions in the same claw and displayed signs of lameness. These animals were therefore classified as 'laminitis positive'. Two animals exposed to oligofructose and all 6 animals in the control group were classified as 'laminitis negative'. Fisher's exact test (one-sided) showed a significant association between oligofructose exposure and development of laminitis $(P=0.03)$.

The postmortem examination of the rumen showed that animals given oligofructose had a mild and diffuse red discoloration of the epithelium, confined to the ventral and cranial parts of the rumen. Mild signs of inflammation were also seen in the cecum and upper colon where lesions was more localized and appeared in stripes. No increase in intestinal wall thickness was observed. Histopathological examination of claw biopsies was carried out and preliminary results are presented in Figures 7 and 8. In summary, clear differences were observed between the lamellar regions of treated and control animals.

\section{DISCUSSION}

Oligofructose is a carbohydrate belonging to the fructan group. It consists of fructose units linked to each other by $\beta$ ( 2 to 1 ) bonds. Fructans are important storage

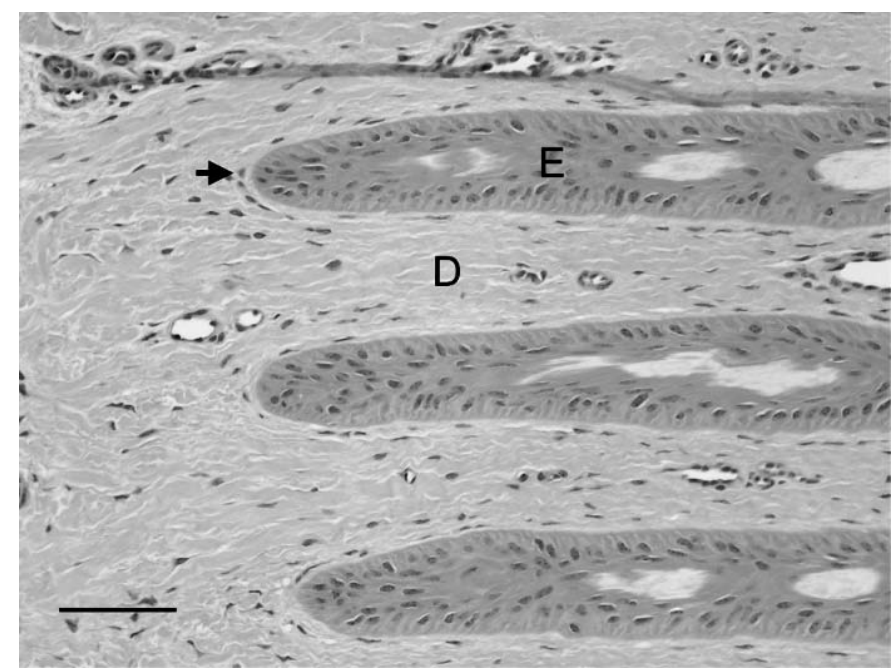

Figure 7. A horizontal claw section of the lamellar region from control animal. Hematoxylin and Eosin $\times 200(\mathrm{bar}=70 \mu \mathrm{m})$. The normal dermo-epidermal junction consists of numerous interlocking dermal (D) and epidermal (E) lamellae. The tips of the epidermal lamellae (arrow) are normally smooth and rounded.

polysaccharides found in common fruits, vegetables, and grasses (Gupta and Kaur, 1997; Longland and Cairns, 2000). The fructan content of some grass types can, under certain growth conditions, reach very high concentrations and a possible role in the pathogenesis of grass-induced laminitis in horses has been proposed (Cairns and Longland, 1998; Longland and Cairns,

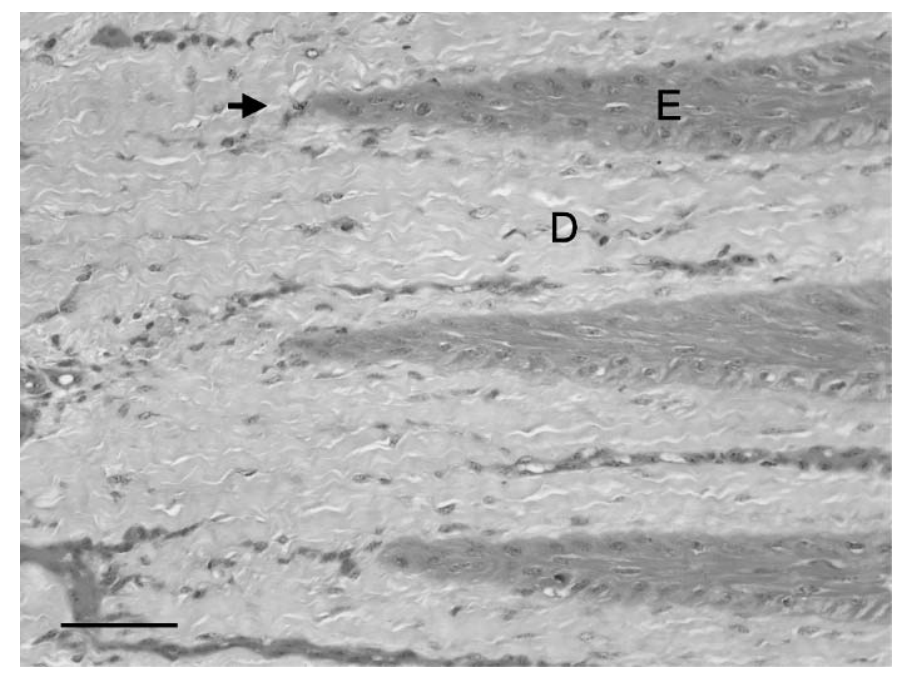

Figure 8. Cross-section of the lamellar region from a heifer given an alimentary oligofructose overload. Hematoxylin and Eosin $\times 200$ (bar $=70 \mu \mathrm{m}$ ). Preliminary results. A common finding was extended epidermal lamellae (E) with pointed tips (arrow) and more cuboidally formed epidermal basal cells than normal. Occasionally dermal hemorrhage and edema was observed. 
2000). This hypothesis has recently been reinforced by an experimental study. It was shown that oral administration of oligofructose did induce acute laminitis in a high percentage of horses (Pollitt and van Eps, accepted). In cattle, the occurrence of lameness in grassfed animals has recently been reviewed (Westwood et al., 2003). It is suggested that ruminal acidosis and laminitis should be considered in the etiology of lameness in pasture-fed dairy herds. The purpose of the present investigation was therefore to examine the clinical response to an alimentary oligofructose overload in dairy heifers.

A direct association between oral oligofructose administration and clinical signs of acute laminitis was demonstrated in 4 of 6 animals, whereas no animals in the control group could be classified as laminitis positive. To the best of our knowledge, this is the first time it has been possible to induce acute bovine laminitis in a high percentage of animals, using an alimentary carbohydrate overload model that parallels the clinical engorgement situation. Additionally, the clinical findings present some interesting similarities to the oligofructose model reported to cause acute laminitis in horses (Pollitt and van Eps, accepted). Oligofructose given at doses of 7.5 to $12.5 \mathrm{~g} / \mathrm{kg}$ caused a transient, watery diarrhea beginning 12 to $16 \mathrm{~h}$ PAO that ceased by 36 to $44 \mathrm{~h} \mathrm{PAO}$, and which coincided with depression and inappetence. No gas distension of colon or cecum was reported. All horses developed metabolic acidosis, mild dehydration, and a transient fever. At 28 to $32 \mathrm{~h}$ PAO, all horses started to show signs of acute laminitis. Thus, despite the differences in hoof anatomy and gastrointestinal function between these 2 species, the similarities in the clinical course of the disease are striking. It therefore seems reasonable to hypothesize that pathogenesis and pathophysiology of oligofructose-induced acute laminitis is similar in both species.

The lameness displayed by 4 of 6 heifers given oligofructose was obvious at the lameness examination, but could easily be overlooked, because animals continued to stand and walk and did not interrupt their eating behavior despite the lameness. In a study of lameness perception, Whay et al. (2002) reported that farmers identified fewer than $25 \%$ of lame cows in their herd. Previous attempts to induce laminitis in cattle did not objectively define how acute laminitis was evaluated clinically (Suber et al., 1979; Andersson, 1981; Boosman et al., 1991). Whay (2002) states that in recognizing lameness it is important not to confine identification and examination only to those individuals showing severe signs. An effort to increase the sensitivity of the lameness examination was therefore sought in the present study. In preparation for objective clinical examination, animals were trained $4 \mathrm{wk}$ before experimentation to accept handling without excitement. Hoof testing was carried out to detect low-grade pain in individual claws, and time intervals between clinical examinations were short. The likelihood of false-positive reactions was decreased by the use of 3 observers alternating in a rotation system, and by strictly defining the signs required for a positive classification. The successful detection of low-grade lameness in the present study suggests that the concept of 'subclinical' laminitis (Hoblet et al., 2000), especially when used in a broader scientific context, should be used with caution. 'Subclinical laminitis' implies that signs are below the threshold of clinical detection. Use of the more diligent examination protocol described here puts in doubt the concept of subclinical laminitis and suggests that most subclinical laminitis is in fact clinical.

Mammals do not possess enzymes to digest fructan directly, but rely on the activity of the intestinal microbiota to degrade the fructose polymers (Longland and Cairns, 2000). Fructanolytic activity has been demonstrated in bacteria isolated from the rumen as well as the equine hindgut (Kasperowicz and Michalowski, 2002; Bailey et al., 2003). The sudden availability of excess fructan, acting as a specific substrate to microorganisms, induces a selective and explosive proliferation of gram-positive bacteria. Recent results of in vitro studies, using equine cecal contents and starch or fructan as the carbohydrate source, have shown that Streptococci and Lactobacilli are the main species involved in bacterial overgrowth. Streptococcus bovis and 5 Lactobacilli spp. were identified as having the capacity to decarboxylate certain amino acids to produce vasoactive amines (Bailey et al., 2003). These results support a theory put forward by Baxter et al. (1989) that substances resulting in vasoconstriction could cause lamellar hypoxia and thereby initiate the development of laminitis. However, a second hypothesis on the pathophysiology of equine laminitis suggests that Strep. bovis exotoxins cause the uncontrolled upregulation of matrix metallo-proteinase activity, which results in enzymatic degradation of basement membrane components (Pollitt and Daradka, 1998; Mungall et al., 2001). The loss of basement membrane anchoring filaments and hemidesmosomes leads to a mechanically unstable dermoepidermal junction. In the horse, detachment of basement membrane is thus followed by displacement of the distal phalanx in the hoof capsule.

A dramatic increase of Strep. bovis (in rumen quantities) was also noted in cattle fed large amounts of concentrates (Tajima et al., 2001). Proliferation of Strep. bovis has been recognized as responsible for excessive production of bacterial mucopolysaccharides, which increases the viscosity of rumen fluid and leads to bloat in feedlot animals (Cheng et al., 1998). In the present 
study, severe abdominal distension due to bloat was not observed. A few animals experienced a brief, transient, and moderate rumen distension at $9 \mathrm{~h}$ PAO, but this coincided with a significant intake of water. Thus, the pathophysiology of the different theories, in relation to bovine and equine laminitis, remains to be investigated. In particular, the extreme complexity of the rumen microbiota and the changes that occur during carbohydrate overload must be addressed.

\section{CONCLUSIONS}

The present article describes the development of a new experimental model for the study of acute laminitis in cattle. An alimentary overload of oligofructose induced a transient period of gastrointestinal disease, which was followed by signs of mild to moderate degrees of lameness in 4 of 6 animals. Training of animals to accept close handling, and a strict definition for the positive classification of laminitis was used to detect clinical cases, which could have been overlooked in a field situation. The model offers a new method that could be used in further investigation of the pathogenesis and pathophysiology of bovine laminitis.

\section{ACKNOWLEDGMENTS}

This work was made possible by the support of the Danish Agricultural and Veterinary Research Council (ref. no. 23-01-0172). Mark Stevens, Abbott Diagnostics, Brisbane kindly provided the i-STAT for blood-gas analyses during the study.

\section{REFERENCES}

Andersson, L. 1981. An attempt to induce laminitis in cows by intraruminal infusion of lactic acid. Acta Vet. Scand. 22:140-142.

Bailey, S. R., M. L. Baillon, A. N. Rycroft, P. A. Harris, and J. Elliott. 2003. Identification of equine cecal bacteria producing amines in an in vitro model of carbohydrate overload. Appl. Environ. Microbiol. 69:2087-2093.

Baxter, G. M., R. E. Laskey, R. L. Tackett, J. N. Moore, and D. Allen. 1989. In vitro reactivity of digital arteries and veins to vasoconstrictive mediators in healthy horses and in horses with early laminitis. Am. J. Vet. Res. 50:508-517.

Bergsten, C. 1994. Haemorrhages of the sole horn of dairy cows as a retrospective indicator of laminitis: An epidemiological study. Acta Vet. Scand. 35:55-66.

Boosman, R. 1990. Bovine Laminitis. Page 156. Ph.D. Thesis. Utrecht, The Netherlands.

Boosman, R., C. W. A. A. M. Mutsaers, and A. Klarenbeek. 1990. Experimental bovine ruminal acidosis associated with endotoxemia and laminitis. Pages 77-93 in Bovine Laminitis. Ph.D. Thesis. Utrecht, The Netherlands.

Boosman, R., C. W. Mutsaers, and A. Klarenbeek. 1991. The role of endotoxin in the pathogenesis of acute bovine laminitis. Vet. Q. $13: 155-162$.

Cairns, A., and A. Longland. 1998. Sugars in grasses - An overview of sucrose and fructan accumulation in temperate grasses. Pages
1-3 in Proc. Int. Res. Conf. on Equine Laminitis. Dodson and Horrell, Ringstead, UK.

Cheng, K. J., T. A. McAllister, J. D. Popp, A. N. Hristov, Z. Mir, and H. T. Shin. 1998. A review of bloat in feedlot cattle. J. Anim. Sci. 76:299-308.

Christmann, U., E. B. Belknap, H. C. Lin, and J. K. Belknap. 2002. Evaluation of hemodynamics in the normal and laminitic bovine digit. Pages 165-166 in Proc. 12th Int. Symp. Lameness in Ruminants, Orlando, FL.

Colam-Ainsworth, P., G. A. Lunn, R. C. Thomas, and R. G. Eddy. 1989. Behaviour of cows in cubicles and its possible relationship with laminitis in replacement dairy heifers. Vet. Rec. 125:573575.

Gupta, A. K., and N. Kaur. 1997. Fructan storing plants - A potential source of high fructose syrups. J. Sci. Ind. Res. 56:447-452.

Hoblet, K., W. Weiss, M. Lowell, and R. Smilie. 2000. Subclinical laminitis in dairy cattle: Maintaining healthy hoof horns. Compend. Contin. Educ. Proc. Vet. 22:97-107.

Hyldgaard-Jensen, J., and M. G. Simesen. 1966. Grutforgiftning hos kvæg. Nord. Vet. Med. 18:73-94.

Kasperowicz, A., and T. Michalowski. 2002. Assessment of the fructanolytic activities in the rumen bacterium Treponema saccharophilum strain S. J. Appl. Microbiol. 92:140-146.

Longland, A. C., and A. J. Cairns. 2000. Fructans and their implications in the aetiology of laminitis. Pages 52-55 in Proc. 3rd Int. Res. Conf. on Feeding Horses. Dodson and Horrell, Ringstead, UK.

Maclean, C. W. 1966. Observations on laminitis in intensive beef units. Vet. Rec. 78:223-231.

Manson, F. J., and J. D. Leaver. 1989. The effect of concentrate:silage ratio and hoof trimming on lameness in dairy cattle. Anim. Prod. 49:15-22.

Momcilovic, D., J. H. Herbein, W. D. Whittier, and C. E. Polan. 2000. Metabolic alterations associated with an attempt to induce laminitis in dairy calves. J. Dairy Sci. 83:518-525.

Morrow, L. L., M. E. Tumbelson, L. D. Kintner, W. H. Pfander, and R. L. Preston. 1973. Laminitis in lambs injected with lactic acid. Am. J. Vet. Res. 34:1305-1307.

Mungall, B. A., M. Kyaw-Tanner, and C. C. Pollitt. 2001. In vitro evidence for a bacterial pathogenesis of equine laminitis. Vet. Microbiol. 79:209-223.

Nelson, A. J., and M. B. Cattell. 2001. Culling and laminitis: Real herds, real cows, real deaths. Bovine Pract. 35:42-45.

Nilsson, S. A. 1963. Clinical, morphological and experimental studies of laminitis in cattle. Acta Vet. Scand. 4(Suppl. 1):188-222.

Offer, J. E., D. McNulty, and D. N. Logue. 2000. Observations of lameness, hoof conformation and development of lesions in dairy cattle over four lactations. Vet. Rec. 147:105-109.

Ohtsuka, H., K. Ohki, T. Tanaka, M. Tajima, T. Yoshino, and K Takahashi. 1997. Circulating tumor necrosis factor and interleukin-1 after administration of LPS in adult cows. J. Vet. Med. Sci. 59:927-929.

Ossent, P., P. R. Greenough, and J. J. Vermunt. 1997. Laminitis. Pages 277 and 279 in Lameness in cattle. 3rd ed. W. B. Saunders, Philadelphia, PA

Pollitt, C. C., and M. Daradka. 1998. Equine laminitis basement membrane pathology: Loss of type IV collagen, type VII collagen and laminin immunostaining. Equine Vet. J. Suppl. 26:139-144.

Pollitt, C. C., and A. W. van Eps. Equine laminitis: Experimental induction with oligofructose. Equine Vet. J. (accepted).

Suber, R. L., J. F. Hentges, J. C. Gudat, and G. T. Edds. 1979. Blood and ruminal fluid profiles in carbohydrate foundered cattle. Am. J. Vet. Res. 40:1005-1008.

Tajima, K., R. I. Aminov, T. Nagamine, H. Matsui, M. Nakamura, and Y. Benno. 2001. Diet-dependent shifts in the bacterial population of the rumen revealed with real-time PCR. Appl. Environ. Microbiol. 67:2766-2774.

Takahashi, K., and B. A. Young. 1981. Effects of grain overfeeding and histamine injection on physiological responses related to acute bovine laminitis. Jpn. J. Vet. Sci. 43:375-385. 
Vermunt, J. J., and P. R. Greenough. 1996. Sole haemorrhages in dairy heifers managed under different underfoot and environmental conditions. Br. Vet. J. 152:57-73.

Webster, A. J. F. 2001. Effects of housing and two forage diets on the development of claw horn lesions in dairy cows at first calving and in first lactation. Vet. J. 162:56-65.

Westwood, C. T., E. Bramley, and I. J. Lean. 2003. Review of the relation between nutrition and lameness in pasture-fed dairy cattle. N.Z. Vet. J. 51:208-218.
Whay, H. R. 2002. A review of current pain management in ruminants. Pages 131-138 in Proc. 12th Int. Symp. on Lameness in Ruminants, Orlando, FL.

Whay, H. R., D. C. J. Main, L. E. Green, and A. J. F. Webster. 2002. Farmer perception of lameness prevalence. Pages 355-358 in Proc. 12th Int. Symp. On Lameness in Ruminants, Orlando, FL.

Yeruham, I., Y. Avidar, U. Bargai, G. Adin, D. Frank, S. Peri, and E. Bogin. 1999. Laminitis and dermatitis in heifers associated with excessive carbohydrate intake: Skin lesions and biochemical findings. J. S. Afr. Vet. Assoc. 70:167-171. 